vantages over the forms of expression more commonly adopted in this country, but Prof. Pearson does well to point out that the supposed fundamental distinction of method claimed by some Continental writers is nonexistent. He himself contributes a very interesting paper on a method of generalising Tchebycheff's first theorem. He finds that the method of approximating to the limits of a probability is unlikely to be of much practical value in the classes of function of usual occurrence. This result does not, of course, deprive Tchebycheff's work of its interest in permitting of the establishment of Bernoulli's theorem and of Poisson's generalisation of that theorem by elementary methods.

Papers of importance both to the student of theoretical statistics and to the practical computer are those of Miss Pairman and Prof. Pearson on the correction of the moment coefficients in limited range frequency distributions, of "Student" on deviations from the Poisson limit to the binomial in actual data, and an editorial, entitled "Peccavimus," correcting errors in various published formulæ.

Those who are ensaged in psychological investigation will turn to Dr. G. H. Thofnson's memoir on psychophysical curves and to the same author's discussion of hicrarchical order among correlation coefficients, a subject to which other recent papers have been devoted. In the miscellamea and in a co-operative study of the eggs of the common tern, the biometrician will find much to interest him. It is invidious to cite any one paper as descrving of special praise, but, from the point of view of practical statistics, the discussion of the correction of moment coefficients in the cases to which the classical method of Sheppard does not apply is of chief interest. The volume includes a touching tribute to the memory of Dr. Charles $B$. Goring, whose untimely death has deprived criminology of one of its most devoted and skilful workers.

\section{THE KINEMATOGRAPH IN SCHOOLS.}

THE use of the kinema for schools, and not merely for school children, has bcen definitely carried a few stages nearer realisation by two recent developments which were brought to the notice of teachers attending the annual meeting of the Geographical Association. In the first place, a portable instrument at the fairly reasonable price of $60 l$. is now on the market. The case itself is fireproof; the lamp is in one separate fireproof chamber within the case, and the film is contained in another, all except the four inches or so actually in the gate; while the instrument is operated by pressing two or three buttons on the outside. The adaptation of the kinema to the class-room in this way has two incidental advantages which are in themselves very great advances. Owing to the fact that the light required is not nearly so strong as for a hall, (1) the instrument can be run off one of the lighting points in the ordinary lighting circuit, and (2) the reduction in light is accompanied by a reduction in heat, so that the film can actually be stopped for some minutes for discussion by the class.

Secondly, the provision of the films seems to be in process of being placed on a more satisfactory basis. Films were used during the war for the instruction of soldiers, and the kinema takes its place in the universitv, notably in the instruction of medical students. The difficulty in the past has been to know what there was to chaose from, and houv to choose what one wanted. It is not casy to choose lantern-slides, and it is less easy still to choose films. It cannot be said that this difficulty is wholly met, but the establishment of the Community Motion Picture Bureau goes a long way towards meeting it. There is, at any rate, somewhere to go to inquire NO. 2622 , VOL. IO4] whether that exists which one desires, and there is a central body which will gradually learn what it is that schools demand, and with the demand will come the supply. The firm receives films and odits them to make them more or less suitable for schools. One of the sessions of the recent annual meeting of the Geographical Association was taken up by a demonstration by Capt. Hodges of the value of the kinema in the teaching of geography. The films showed varied greatly in quality; the most ambitious, an American film dealing with the life-history of a volcano, was the least successful for several reasons, the most fundamental of which was that it suffered from the distinctly American failing of being nonregional. Other films, dealing with Egypt and the Nile, lumberins, and coffec culture in Java, could very easily be fitted without any jars into geography courses. This is, perhaps, not all that is desired, but it shows, at any rate, that the problem is being tackled, and that there is every prospect of a satisfactory solution ere long.

\section{IRRICITION IN EGIPT.}

$W^{T E}$ had occasion in Nature of September is and October 9 last to allude to the controversy which has arisen out of the proposals put forward by the Egyptian Government, under British advice, for the development of the agricultural districts of Egypt and the Sudan by means of additional irrigation works on a very extensive scale. The controversy culminated in the appointment of a Foreign Office Committee, which sat in London to inquire into the charges brought by Sir William Willcocks against the Egyptian Public Works Department. The Committee's findings exonerated the Department, but failed to satisfy Sir WVilliam, who forthwith reiterated and amplified his accusations with increased vehemence. Criticism so trenchant and persistent from an engineer of undoubted standing and experience could not be ignored, and now it has been decided to submit the whole question to an International Commission consisting of three members-an irrigation engineer, nominated by the Government of India, as president; a British physicist, nominated by the University of Cambridge; and an irrigation engineer, nominated by the Government of the Cinited States. The terms of reference are:- "To advise the Egyptian Government upon the projects prepared by the Public Works Department, with a view to the further regulation of the Nile for the benefit of Egypt and the Sudan, and in particular to examine and report upon the physical data upon which the projects rest, and to report upon the propriety of the manner in which, as the result of these projects, the increased supplv of available water thereby provided will be allocated at each stage of development between Erypt and the Sudan, and to advise as to the apportionment of the cost as between Fgypt and the Sudan." In a matter so seriously affecting the welfare and development of two important countries, it is to be hoped that the decisions arrived at by the Commission will be such as to command a general consensus of expert approval.

The Cairo correspondent of the Times states, in a message published in the issue of January 23. that the Commission is coristituted as follows:-Mr. F. St. John Gebbie, Chief Engineer, Bombay, who was last engaged on the Sukkur barrage scheme-nominated by the Indian Government (chairman); Dr. G. C. Simpson, meteorologist at Simla-nominated by Cambridge University; and $\mathrm{Mr}$. H. T. Cory, who directed the Salton sea works, California. in roo-nominated by the American Government. Mr. J. I.. Capes, of the Egrotian Ministry of Education, will be serretary of the Commission. 